\title{
Therapy-related Changes of $\mathrm{CD}^{+} \mathrm{O}^{+}$and $\mathrm{CD}_{45 \mathrm{RO}^{+}}$ Lymphocyte Subsets in Chronic Myeloid Leukemia (CML): An Immunohistochemical and Morphometric Study on Sequential Trephine Biopsies of the Bone Marrow
}

Juergen Thiele, M.D., Hans Michael Kvasnicka, M.D., Annette Schmitt-Graeff, M.D., Gabriela Cvetanovska, Nicole Blum, Hans Eckart Schaefer, M.D.

Institutes of Pathology, Universities of Cologne (JT, HMK, GC, NB) and Freiburg (ASG, HES), Germany

Little information exists about the amount of

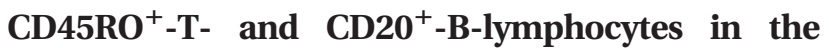
bone marrow of patients with Philadelphia chromosome-positive chronic myelogenous leukemia $\left(\mathrm{Ph}^{1+}-\mathrm{CML}\right)$ at presentation or regarding corresponding changes during therapy. On the other hand, quantification of this cell compartment seems to be imperative for two reasons: first, the presumed association of immunocompetent lymphocyte subsets in the expansion of the leukemic cell clone; and second, a speculated relationship with the complex generation of myelofibrosis. Therefore, an immunohistological and morphometric study was performed on 219 representative trephine biopsies of the bone marrow derived from 70 patients with repeated examinations during the course of $\mathbf{P h}^{1+}$-CML. For the identification of the different lymphocyte populations, the monoclonal antibodies UCHL-1 (CD45R0) and L26 (CD20) were applied on formaldehyde-fixed and decalcified specimens. In comparison to a control group and calculated per hematopoietic cells, the CML bone marrow showed about a $50 \%$ decrease in the total amount of lymphocytes. Determination of $\mathrm{CD} 5 \mathrm{RO}^{+}$and $\mathrm{CD}^{+}{ }^{+}$subsets revealed a significant enhancement during treatment. Because of the different intervals (range, 10 to 25 mo) between first and last biopsy in the various therapeutic groups, results had to be modified by considering dynamic features. This calculation included changes of the lymphocyte subpopulations related to time. Contrasting the $\mathrm{CD}^{4} 5 \mathrm{RO}^{+}$lymphocytes, a relevant in-

Copyright (C) 2000 by The United States and Canadian Academy of Pathology, Inc.

VOL. 13, NO. 8, P. 888, 2000 Printed in the U.S.A.

Date of acceptance: February 16, 2000.

Address reprint requests to: Juergen Thiele, M.D., Institute of Pathology,

University of Cologne, Joseph-Stelzmannstr.9, D-50924 Cologne, Ger-

many; e-mail: j.thiele@uni-koeln.de; fax: 49-0221-4786360. crease in the $\mathrm{CD}^{+}{ }^{+}$subset could be observed after interferon- $\alpha$ treatment or corresponding combination regimens. No significant correlations were found between fiber density at onset (first biopsy) or development of fibrosis and lymphocyte proliferations in the course of CML. Our results are in keeping with the finding that a proper immune response consistent with an increased lymphocyte growth seems to be associated with a regression of the clonally-transformed cell population. Opposed to a repeatedly discussed pathomechanism, we failed to demonstrate any quantitative relationships between the extent of lymphocyte proliferations and occurrence or progression of myelofibrosis.

KEY WORDS: B - $\left(\mathrm{CD20}^{+}\right)$lymphocytes, Chronic myelogenous leukemia, Fibrosis, $\mathrm{T}-\left(\mathrm{CD}^{2} \mathrm{RO}^{+}\right)$ lymphocytes, Therapeutic effects.

Mod Pathol 2000;13(8):888-896

Interest in the lymphocyte population in chronic myelogenous leukemia (CML) has been reawakened because of problems related to cell lineage involvement (1-7), lymphoid blast crisis (8-10), and occurrence of acute graft-versus-host disease (aGVHD) complicating allogeneic bone marrow transplantation (11-13). There is convincing cytogenetic, enzymatic, and molecular biologic evidence suggesting a clonal transformation of B- and T-lymphocytes; however, a conflict of opinion arises concerning its exact extent (2-7). It is generally accepted that certain subsets of T-lymphocytes $\left(\mathrm{CD}^{+}\right.$and $\left.\mathrm{CD}^{+}\right)$are involved in the alloreactive response after transplantation causing aGVHD as a most hazardous complication $(11,12)$. Contrasting this progress in the understanding of important biological features regarding the lymphoid cell population in CML, little knowledge exists about their exact quantity in comparison to the normal bone 
marrow (14). Moreover, the paucity of lymphocytes within the hematopoietic tissue has significantly hampered any investigations attempting to elucidate alterations during chemotherapy or interferon administration. In vitro studies are in keeping with the assumption that the bone marrow stromal cells selectively induce a lineage-specific commitment of the myeloid and lymphoid progenitors $(15,16)$. One of the effects of interferon- $\alpha$ (IFN) is to restore non-clonally transformed hematopoiesis in CML by a restitution of normal responsiveness to the negative regulation of the microenvironment (17-19). In this context, the question arises whether (and to what extent) the lymphoid lineage is involved in these complex pathomechanisms of IFN action. Finally, in chronic myeloproliferative disorders (CMPDs), which eventually evolve into myelofibrosis, disturbances of the autoimmune system or an activation of the complement system have been repeatedly discussed (20-23). Concerning this speculation, an ill-defined interaction of immune complexes mediated by T-lymphocyte subsets with the myelofibrosis-promoting factor release by the megakaryocyte lineage was hypothesized (24-26).

For this reason, the purpose of the present immunohistochemical and morphometric study was (1) to quantify B-CD20 ${ }^{+}$and T-CD45RO ${ }^{+}$lymphocyte subsets in the CML bone marrow in comparison to a control group; (2) to assess their alterations following various therapeutic regimens; (3) to elucidate correlations between reticulin fiber density and lymphocyte populations, including changes of myelofibrosis during the course of disease.

\section{PATIENTS AND METHODS}

\section{Patients}

Criteria for entry of patients with Philadelphia chromosome-positive $\left(\mathrm{Ph}^{1+}\right) \mathrm{CML}$ into this retrospective study included representative bone marrow biopsies on admission and at standardized intervals during the course of treatment. Therefore, from our files we selected 219 specimens derived from 70 patients with repeatedly performed bone marrow biopsies and a complete clinical follow-up with strictly defined therapeutic regimens. Diagnosis of $\mathrm{Ph}^{1+}$-CML was confirmed by generally accepted clinical, morphologic, and cytogeneticmolecular biological findings and included only patients in stable phase with less than $15 \%$ myeloblasts and promyelocytes in the peripheral blood (Table 1). Our cohort was divided into different therapy groups (Table 2): a historical small group with busulfan (BU) treatment (group I), a second (group II) receiving monotherapy by interferon- $\alpha$ (IFN), a third (group III) with single agent hydroxyurea (HU) administration, another with a
TABLE 1. Hematological Characteristics of the 70 Patients with $\mathbf{P h}^{1+}$-CML Under Study

\begin{tabular}{|c|c|}
\hline Parameter & Mean $\pm \mathrm{SD}$ \\
\hline Leukocytes $\left(\times 10^{9} / \mathrm{L}\right)$ & $112 \pm 104$ \\
\hline Polymorphonuclear & $46.1 \pm 16.4$ \\
\hline \multicolumn{2}{|l|}{ Granulocytes } \\
\hline Myeloblasts (\%) & $2.4 \pm 3.7$ \\
\hline Promyelocytes (\%) & $2.8 \pm 2.9$ \\
\hline Myelocytes (\%) & $12.1 \pm 7.3$ \\
\hline Normo-erythroblasts (\%) & $1.0 \pm 2.3$ \\
\hline Eosinophils (\%) & $2.7 \pm 3.2$ \\
\hline Basophils (\%) & $4.3 \pm 4.0$ \\
\hline Lymphocytes (\%) & $9.6 \pm 8.4$ \\
\hline Erythrocytes $\left(\times 10^{12} / \mathrm{L}\right)$ & $4.0 \pm 0.6$ \\
\hline Hemoglobin $(\mathrm{g} / \mathrm{dL})$ & $12.8 \pm 1.8$ \\
\hline Platelets $\left(\times 10^{9} / \mathrm{L}\right)$ & $539 \pm 436$ \\
\hline $\mathrm{LDH}(\mathrm{U} / \mathrm{L})$ & $622 \pm 316$ \\
\hline $\operatorname{ALP}(\text { score })^{a}$ & $13 \pm 25$ \\
\hline Spleen size ${ }^{b}$ & $2.1 \pm 2.9$ \\
\hline Liver $\operatorname{size}^{b}$ & $0.4 \pm 0.8$ \\
\hline
\end{tabular}

${ }^{a}$ ALP-alkaline leukocyte phosphatase - normal score 20-80

${ }^{b}$ Spleen-Liver size - cm below costal margin.

combined treatment by IFN plus HU (group IV), and finally, patients with miscellaneous treatment regimens (group V). The latter included various combinations of $\mathrm{BU}$ and especially vincristine. Monotherapy by BU (group I) was applied at a daily dose of $0.1 \mathrm{mg} / \mathrm{kg}$ until the leukocyte count dropped below $20 \times 10^{9} / \mathrm{L}$ and treatment was resumed at a count of more than $50 \times 10^{9} / \mathrm{L}$. IFN monotherapy (group II) included 6 to $9 \times 10^{6}$ units/ $\mathrm{m}^{2}$ /day as an initial dose followed by an appropriate maintenance treatment ( 2 to $6 \times 10^{6}$ units) in accordance with leukocyte counts and toxicity. Group III comprised patients with single agent HU therapy with daily doses ranging between 20 to 40 $\mathrm{mg} / \mathrm{kg}$ and adapted to peripheral blood counts. In group IV patients, HU was given as a daily dose starting from $40 \mathrm{mg} / \mathrm{kg}$ for 3 to 4 mo accompanying IFN administration. As a control group, a cohort of 20 age- and sex-matched patients without bone marrow pathology (but with slight to moderate osteoporosis) was included in this study.

\section{Bone Marrow Biopsies}

Trephine biopsies of the bone marrow (mean size, $14.4 \times 1.7 \mathrm{~mm}$ ) were performed from the posterior iliac crest while the patients were still under therapy for at least 6 mo following CML diagnosis. More than two, but mostly three sequential biopsies were carried out in seven patients of group I, in 11 patients of group II, in 12 patients of group III, in six patients of group IV, and in 11 patients of group V. Fixation was done in a lowconcentrated aldehyde solution $(2 \mathrm{~mL} 25 \%$ glutaraldehyde, $3 \mathrm{~mL} 37 \%$ formaldehyde, $1.58 \mathrm{~g}$ anhydrous calcium acetate, and distilled water per 100 $\mathrm{mL}$ ) for 12 to 48 hours. Further processing included decalcification for 3 to 4 days in $10 \%$ buffered 


\begin{tabular}{|c|c|c|c|c|c|}
\hline \multirow[b]{2}{*}{ Group of patients } & \multicolumn{5}{|c|}{ Therapy Group } \\
\hline & I & II & III & IV & $\mathrm{V}$ \\
\hline & BU & IFN & HU & $\mathrm{IFN}+\mathrm{HU}$ & Miscellaneous \\
\hline No. of patients & 8 & 26 & 17 & 7 & 12 \\
\hline Age (median, years) & 58 & 37 & 38 & 53 & 51 \\
\hline Gender (male/female) & $4 / 4$ & $18 / 8$ & $9 / 8$ & $5 / 2$ & $5 / 7$ \\
\hline Interval between first and last biopsy (months) & 25 & 10 & 15 & 21 & 12 \\
\hline
\end{tabular}

BU, busulfan; IFN, interferon- $\alpha$; HU, hydroxyurea.

ethylene-diamine tetra-acetic acid (EDTA), $\mathrm{pH} 7.2$, paraffin embedding, and the use of several routine staining techniques involving Giemsa, periodic acid-Schiff reagent, naphthol-AS-D-chloroacetate esterase, Perls' reaction for iron, and the silver impregnation method (Gomori's technique). For a specific staining of lymphocyte subsets, appropriate monoclonal antibodies were selected to detect the following epitopes: CD20 (L26) for the identification of B-lymphocytes (27) and CD45R0 (UCHL-1) to characterize T-lymphocytes (28). Regarding UCHL-1, it has been recognized that this antibody shows cross-reactivity with some myeloid and monocytic cells in frozen-sections and smears. However, this nonspecific staining is significantly reduced in marrow samples after mild decalcification by edetic acid, which was applied in this study $(14,29)$. Moreover, for a comparative evaluation of T-lymphocyte subsets, we performed a pilot study on 25 randomly selected bone marrow trephines at diagnosis of CML involving the monoclonal antibody CD3 (30). Considering the very few data on immunohistochemical quantifications of lymphocyte subsets in paraffin-embedded normal and in particular CML bone marrow specimens that are so far available, exclusively UCHL-1 was involved (14, 29). For this reason, we explicitly focused on $\mathrm{CD}_{4} \mathrm{RO}^{+}$-reactivity for a better comparison with previous findings. The monoclonal antibody and other reagents were purchased from DakoDiagnostica GmbH (Hamburg, Germany). Details of staining procedures (APAAP-method) were reported in detail in previous communications (27, $28,31)$.

\section{Morphometry}

After immunostaining, we performed morphometric analysis by two manual optic planimeters (MOP-A-MO1-Kontron and VIDAS-Zeiss-Kontron) with a standard program set (Kontron software) on large trephine biopsies with an artifact-free mean marrow area of $8.3 \pm 2.5 \mathrm{~mm}^{2}$. Frequency of CD20 ${ }^{+}$ and CD45R0 ${ }^{+}$lymphocytes per $\mathrm{mm}^{2}$ was determined at $500 \times$ magnification by regarding not only the total marrow including adipose tissue, but also the hematopoietic area of the trephine biopsy available for evaluation. Because there may be a minor cross-reactivity of the monoclonal antibody UCHL-1 with myeloid and histiocytic cells (30), only those cells were regarded as $\mathrm{CD}_{4} 5 \mathrm{RO}^{+}$that showed also the cytological characteristics of lymphocytes. Argyrophilic (reticulin and collagen) fiber density was assessed following silver impregnation (Gomori's stain) by using an ocular grid and expressed as numbers of intersections (i) per $\mathrm{mm}^{2}$ bone marrow area and also per fat cell-free hematopoietic tissue (so called point-intersection method). Reference of all data to total marrow area and to cellularity (hematopoietic area) was necessary to avoid the erroneous impression of a reduction of lymphocytes and fiber density in the sequential biopsies due to the expansion of adipose tissue or interstitial edema following therapy. Morphometric measurements were made by four individuals and regularly verified by two others for accuracy.

\section{Statistical Analysis}

Statistical evaluation included calculation of Pearson's correlation coefficients between the various hematologic and morphometric parameters. Because of the varying intervals between sequential biopsies in the different therapeutic groups (Table 2) and in individual patients, assessment of alterations regarding frequency of lymphocytes and fiber density had to be carried out in relation to time and quantity. Accordingly, dynamic features were determined by using indices consisting of the ratios between differences (increase-decrease) of histologic variables (lymphocytes, fibers) and time (t) consistent with the interval (in months) between first and last bone marrow biopsies ( $\Delta$ variable $/ \Delta \mathrm{t}$ $\times 10^{2}$ ). Following this rationale a so-called lymphocyte proliferation/regression index (LPI/LRI) and a myelofibrosis proliferation/regression index (MPI/ MRI) were calculated.

\section{RESULTS}

Staining reactions with the applied monoclonal antibodies against $\mathrm{CD}^{2} 5 \mathrm{RO}^{+}$and $\mathrm{CD}^{+} 0^{+}$lymphocyte subsets proved to be very distinctive and revealed either randomly scattered cells (Fig. 1, A-B) or infrequently lymphoid nodules (Fig. 1, C-D). 


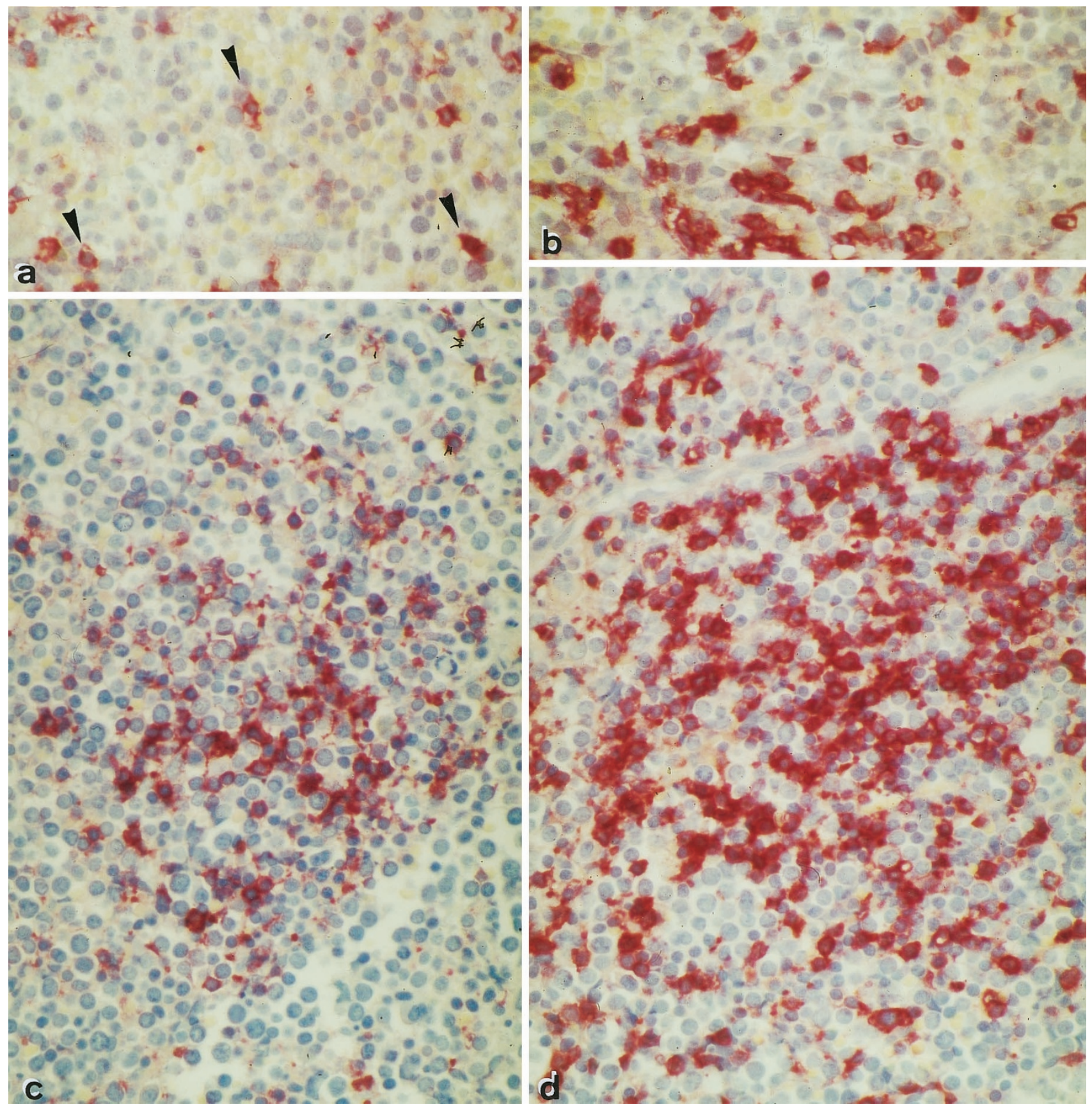

FIGURE 1. A, several dispersed CD20 $0^{+}$-B-lymphocytes (arrows) contrasting the significantly denser population of CD45RO ${ }^{+}-\mathrm{T}$-lymphocytes (B). Lymphoid nodule with a randomly scattered population of $\mathrm{CD} 20^{+}$-lymphocytes $(\mathbf{C})$ and a more frequently detectable $\mathrm{CD}_{4} 5 \mathrm{RO}^{+}$lymphoid cell population (D) (original magnification, $370 \times$ ).

Morphometric analysis showed that in the pretreatment biopsies of CML patients the ratio between $\mathrm{T}$ and B-lymphocytes calculated per hematopoietic cells was approximately 4:1 (Table 3 ), which was comparable to our controls. Concerning the T-lymphocyte subset and UCHL-1 specificity, the CD3-stained control group revealed an amount of positive cells ranging between $95 \%$ and $97 \%$ of the $\mathrm{CD}_{45 \mathrm{RO}^{+}}$population. This neglectable difference was probably due to a positive staining of a few histiocytic cells, which, however, were recognized by our morphometric evaluation and discarded from further calculations. Considering the significant expansion of fat cells in the normal adult bone marrow opposed to the hypercellularity in CML ( $48 \%$ versus $98 \%$ ), the absolute number of lymphocytes within the hematopoietic cell compartment was decreased to about $50 \%$ (Table 3). No quantitative relationships could be ascertained between the number of lymphocytes in the peripheral blood and the corresponding lymphoid compartment $\left(\mathrm{CD} 45 \mathrm{RO}^{+}\right.$plus $\left.\mathrm{CD} 20^{+}\right)$in the marrow.

Following various therapeutic regimens an overall two- to three-fold increase in the $\mathrm{CD}_{4} 5 \mathrm{RO}^{+}$- and 


\begin{tabular}{|c|c|c|c|c|c|c|c|c|c|c|c|}
\hline \multicolumn{12}{|c|}{ Therapy } \\
\hline \multirow[b]{2}{*}{ No. of biopsies } & \multicolumn{2}{|c|}{$\begin{array}{c}\mathrm{I} \\
\mathrm{BU}\end{array}$} & \multicolumn{2}{|c|}{$\begin{array}{c}\text { II } \\
\text { IFN }\end{array}$} & \multicolumn{2}{|c|}{$\begin{array}{l}\text { III } \\
\text { HU }\end{array}$} & \multicolumn{2}{|c|}{$\begin{array}{c}\text { IV } \\
\text { IFN + HU }\end{array}$} & \multicolumn{2}{|c|}{$\begin{array}{c}\text { V } \\
\text { Miscellaneous }\end{array}$} & \multirow{2}{*}{$\begin{array}{c}\begin{array}{c}\text { VI } \\
\text { Control }\end{array} \\
-\end{array}$} \\
\hline & 1st & Last & $1 \mathrm{st}$ & Last & 1 st & Last & 1st & Last & $1 \mathrm{st}$ & Last & \\
\hline $\begin{array}{l}\text { Cellularity - } \\
\text { hematopoiesis (\%) }\end{array}$ & $97 \pm 6$ & $89 \pm 22$ & $99 \pm 3$ & $83 \pm 18$ & $99 \pm 1$ & $93 \pm 15$ & $96 \pm 5$ & $80 \pm 20$ & $98 \pm 3$ & $88 \pm 20$ & $48 \pm 5$ \\
\hline $\begin{array}{l}\mathrm{CD} 45 \mathrm{RO}^{+}- \\
\text {lymphocytes }\left(\mathrm{mm}^{2}\right)\end{array}$ & $\begin{array}{c}15 \pm 7 \\
(16 \pm 7)\end{array}$ & $\begin{array}{c}26 \pm 16 \\
(29 \pm 16)\end{array}$ & $\begin{array}{c}17 \pm 7 \\
(18 \pm 8)\end{array}$ & $\begin{array}{l}25 \pm 8 \\
(32 \pm 12)\end{array}$ & $\begin{array}{c}16 \pm 12 \\
(16 \pm 12)\end{array}$ & $\begin{array}{l}30 \pm 21 \\
(31 \pm 21)\end{array}$ & $\begin{array}{c}11 \pm 6 \\
(11 \pm 6)\end{array}$ & $\begin{array}{l}29 \pm 14.5 \\
(35 \pm 13)\end{array}$ & $\begin{array}{l}13 \pm 4.9 \\
(13 \pm 5)\end{array}$ & $\begin{array}{c}47 \pm 34 \\
(59 \pm 52)\end{array}$ & $\begin{array}{c}15 \pm 8 \\
(28 \pm 11)\end{array}$ \\
\hline $\begin{array}{l}\text { CD20 }{ }^{+} \text {-lymphocytes } \\
\left(\mathrm{mm}^{2}\right)\end{array}$ & $\begin{array}{c}4 \pm 2 \\
(4 \pm 2)\end{array}$ & $\begin{array}{c}9 \pm 13 \\
(10 \pm 11)\end{array}$ & $\begin{array}{c}7 \pm 7 \\
(7 \pm 7)\end{array}$ & $\begin{array}{l}14 \pm 11 \\
(17 \pm 14)\end{array}$ & $\begin{array}{c}4 \pm 3 \\
(4 \pm 3)\end{array}$ & $\begin{array}{c}7 \pm 6 \\
(7 \pm 7)\end{array}$ & $\begin{array}{c}4 \pm 3 \\
(4 \pm 4)\end{array}$ & $\begin{array}{l}15 \pm 9 \\
(19 \pm 15)\end{array}$ & $\begin{array}{c}4 \pm 2 \\
(4 \pm 2)\end{array}$ & $\begin{array}{c}8 \pm 14 \\
(8 \pm 14)\end{array}$ & $\begin{array}{c}5 \pm 1 \\
(8 \pm 4)\end{array}$ \\
\hline $\begin{array}{l}\text { Fiber density } \\
\qquad\left(\mathrm{i} \times 10^{2} / \mathrm{mm}^{2}\right)\end{array}$ & $\begin{array}{c}44 \pm 35 \\
(45 \pm 35)\end{array}$ & $\begin{array}{c}73 \pm 52 \\
(79 \pm 48)\end{array}$ & $\begin{array}{l}30 \pm 20 \\
(30 \pm 20)\end{array}$ & $\begin{array}{c}52 \pm 23 \\
(65 \pm 28)\end{array}$ & $\begin{array}{c}40 \pm 19 \\
(40 \pm 19)\end{array}$ & $\begin{array}{c}47 \pm 47 \\
(50 \pm 46)\end{array}$ & $\begin{array}{l}34 \pm 14 \\
(35 \pm 13)\end{array}$ & $\begin{array}{c}43 \pm 20 \\
(53 \pm 20)\end{array}$ & $\begin{array}{c}39 \pm 22 \\
(40 \pm 22)\end{array}$ & $\begin{array}{c}54 \pm 63 \\
(60 \pm 37)\end{array}$ & $\begin{array}{c}8 \pm 3 \\
(16 \pm 8)\end{array}$ \\
\hline
\end{tabular}

BU, busulfan; IFN, interferon- $\alpha$; HU, hydroxyurea; i, intersections.

Values (mean $\pm \mathrm{SD}$ ) are given for total marrow area and for hematopoiesis - cellularity (brackets). There is a significant $(P<.05)$ increase in CD45R0 ${ }^{+}$ and $\mathrm{CD} 20^{+}$lymphocytes in each therapy group (paired T test).

$\mathrm{CD} 20^{+}$lymphocyte population was detectable between first and last examination (Table 3). This feature was most pronounced when related to the amount of hematopoiesis, which was particularly reduced under IFN and/or HU combination therapy. In line with these changes affecting the dispersed lymphocytes, lymphoid nodules were found at a very low frequency (3 to $5 \%$ ) in the biopsies on admission. On the other hand, after therapy these were significantly enhanced in number (12 to $13 \%$ ). In these aggregates, a predominance of $\mathrm{CD}_{4} 5 \mathrm{RO}^{+}$lymphocytes was evident (Fig. 2, A-B) similar to the corresponding lesions in the pretreatment specimens (Fig. 1, C-D). Alterations involving the lymphocyte subsets became most prominent when calculating dynamic parameters characterizing speed and extent of lymphocyte growth. As may be derived from Table 4, a relevant increase in the $\mathrm{CD} 45 \mathrm{RO}^{+}$lymphoid population was recognizable following treatment with IFN, HU, and miscellaneous regimens. Contrasting this finding, the $\mathrm{CD} 20^{+}$subset revealed a significant enhancement especially in therapeutic groups including IFN alone or a corresponding combination treatment (Table 4). These features were prominently expressed in patients presenting with hematologic remission.

Finally, no significant correlations could be determined between content of (reticulin) fibers at presentation of patients (first biopsy) and during therapy (last biopsy) with the number of $\mathrm{CD} 20^{+}$or $\mathrm{CD} 45 \mathrm{RO}^{+}$lymphocytes or the total lymphocyte

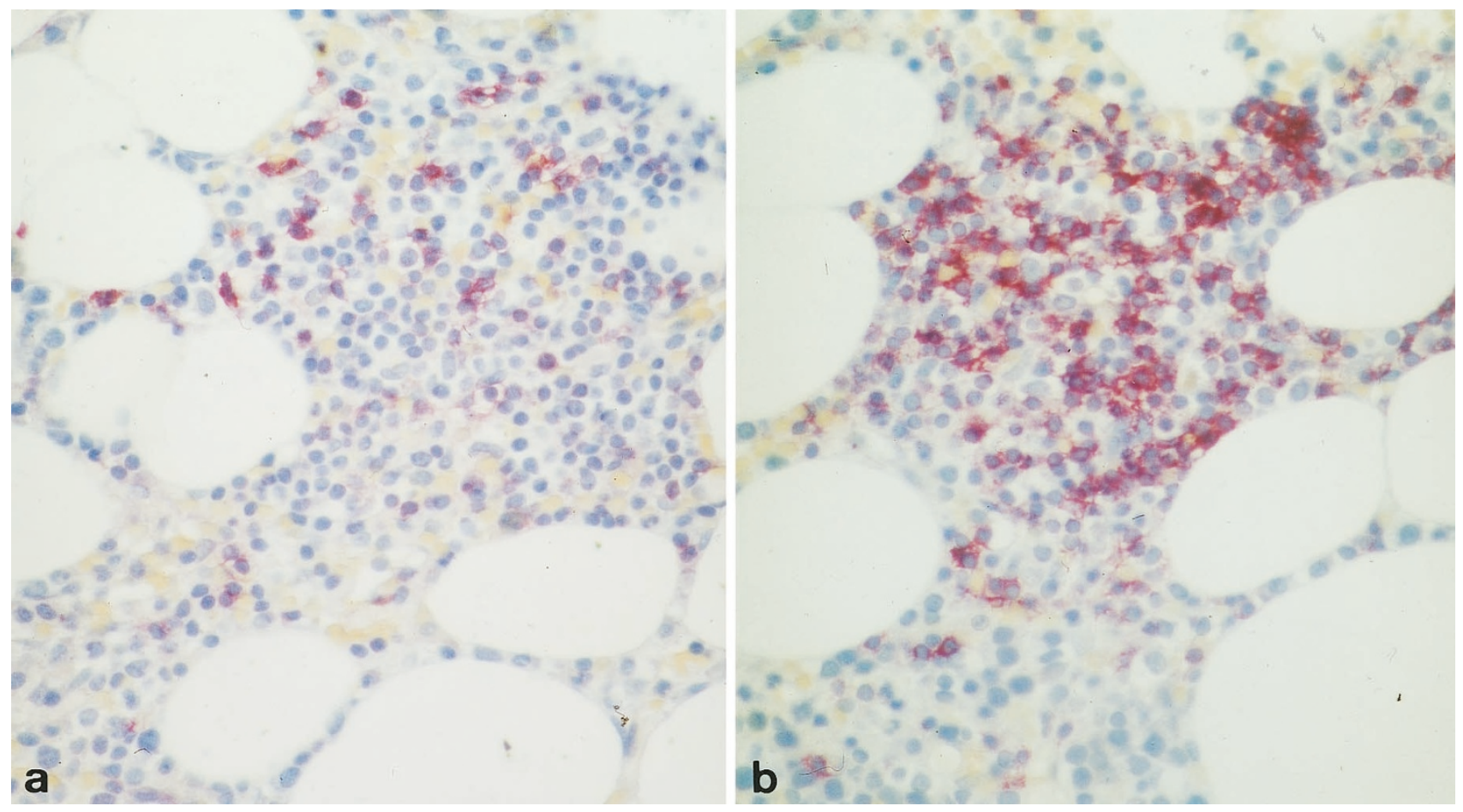

FIGURE 2. Lymphoid nodules following therapy of CML with IFN results in a decrease of cellularity with reappearance of adipocytes. A, few $\mathrm{CD} 20^{+}$-B-lymphocytes opposed to many CD45RO ${ }^{+}$-T-lymphocytes (B) are composing the lymphoid aggregate (original magnification, $370 \times$ ). 


\begin{tabular}{|c|c|c|c|c|c|}
\hline & \multicolumn{5}{|c|}{ Therapy Group } \\
\hline & I & II & III & IV & $\mathrm{V}$ \\
\hline & BU & IFN & HU & $\mathrm{IFN}+\mathrm{HU}$ & Miscellaneous \\
\hline \multicolumn{6}{|l|}{$\begin{array}{l}\text { Lymphocyte } \\
\text { proliferation/regression (LPI/LRI) }\end{array}$} \\
\hline Total lymphocyte population & 66 & 122 & 77 & 141 & 269 \\
\hline$\left(\Delta \mathrm{CD} 45 \mathrm{RO}^{+}+\Delta \mathrm{CD} 20^{+}\right) / \mathrm{t} \times 10^{2}$ & $(68)$ & $(166)$ & $(94)$ & $(147)$ & $(381)$ \\
\hline T-lymphocyte subset & 29 & 46 & 90 & 109 & 292 \\
\hline$\Delta \mathrm{CD}^{2} 5 \mathrm{RO}^{+} / \mathrm{t} \times 10^{2}$ & $(30)$ & $(96)$ & $(90)$ & (159) & $(357)$ \\
\hline B-lymphocyte subset & 4 & 81 & 8 & 46 & -6 \\
\hline$\Delta \mathrm{CD}^{2} 0^{+} / \mathrm{t} \times 10^{2}$ & $(5)$ & $(86)$ & $(8)$ & $(47)$ & $(-4)$ \\
\hline \multicolumn{6}{|l|}{ Myelofibrosis progression } \\
\hline - MPI - & 68 & 185 & -26 & 37 & 61 \\
\hline$\Delta$ fibers $/ \mathrm{t}$ & $(75)$ & $(230)$ & $(3.5)$ & $(69)$ & $(55)$ \\
\hline
\end{tabular}

BU, busulfan; IFN, interferon- $\alpha$; HU, hydroxyurea.

Dynamic features shown are indices between first and last biopsy of CD45RO ${ }^{+}$and CD20 ${ }^{+}$lymphocyte subsets and myelofibrosis (median values) according to therapy groups calculated per $\mathrm{mm}^{2}$ total bone marrow area and hematopoiesis-cellularity (brackets). The striking disparity within both values in certain groups (II, IV, V) is due to changes in cellularity (Table 3).

population (Table 3). The myelofibrosis progression index (MPI) disclosed no relevant association with the corresponding indices signaling dynamics of lymphocyte growth (Table 4).

\section{DISCUSSION}

Although immunohistochemical investigations of lymphocyte subsets can be easily performed on cryostat sections, this involves technical problems that generally have prevented the introduction of such methods into routine practice of hematopathology $(32,33)$. This shortcoming has also significantly impaired a more elaborate evaluation of a large number of bone marrow specimens. First of all, a conflict of opinion still persists regarding the exact number or ratio of T- and B-lymphocytes in the normal bone marrow. According to immunohistologic analysis of bone marrow frozen sections, the ratio is about $9 \%$ T-lymphocytes $\left(2.7 \% \mathrm{CD}^{+}\right.$ and $\left.6.3 \% \mathrm{CD}^{+}\right)$to $1.5 \%\left(\mathrm{CD} 22^{+}\right)$B-lymphocytes (33). This T- to B-cell ratio is generally comparable with the CD45R0- and CD20-reactivity of lymphocyte subsets in paraffin-embedded bone marrow trephine biopsies amounting between 4:1 and 5:1 (14). Second, specificity of UCHL-1 or CD45RO ${ }^{+}$for the total T-lymphocyte subset should be discussed. In this context, it has to be emphasized that the monoclonal antibody UCHL-1 (28), opposed to CD3 (30), has been found to show a neglectable cross reactivity with myeloid cells in samples after mild decalcification by chelating agents such as edetic acid $(14,29)$ as was applied in this study. A putative positive staining of a few histiocytic cells was recognized during morphometric evaluation of the bone marrow samples, but not regarded in our calculations. In confirmation and extension to previous findings $(14,33)$, morphometric quantification on paraffin sections derived from our control group of patients showed a similar ratio (4:1) be- tween $\mathrm{CD}_{45 \mathrm{RO}^{+}}$and $\mathrm{CD} 20^{+}$lymphocytes in hematopoietic tissue (Table 2). On the other hand, a more comprehensively conducted comparison between normal and CML bone marrow specimens has to regard cellularity (i.e., the amount of hematopoiesis). This reference value is significantly different because it reveals a $48 \%$ cellularity in an age-matched control population contrasting with about $98 \%$ in CML patients (Table 2). Taking this feature into account, in the CML bone marrow an overall $50 \%$ regression in the total lymphocyte population is observable. In particular, the fact that $\mathrm{T}$-cell numbers are significantly decreased in relation to total hematopoiesis merits attention. It is tempting to speculate that a breakdown in immune homeostasis may have occurred in CML, generating a suppression of activation of immunocompetent cells and consequently may further the expansion of the leukemic clone $(11,12)$.

A wealth of data has been gathered in recent years concerning the action of $\mathrm{HU}$ and IFN as the currently preferred treatment modalities in CML patients, either as single agents or in various combinations (34-36). However, controversy and discussion arises when trying to elucidate the exact pathways of IFN action on the leukemic cell clone $(37,38)$. Unlike the most popular HU, which is a structurally simple antimetabolite that interferes with DNA synthesis by inhibiting ribonucleotide reductase activity (35), a conflict of opinions has emerged regarding the corresponding pathogenetic model for IFN. IFN therapy facilitates an induction of a major hematologic remission in about $80 \%$ of patients and a complete cytogenetic response in a few patients, resulting in significantly prolonged survival $(39,40)$. Based on experimental data, two possibilities of IFN actions on the CML bone marrow are currently under discussion. The first involves the immune system because the interferon family of immune modulators is capable of increas- 
ing natural killer cell (NK) cytotoxicity within a few hours of in vitro exposure (41). It has been demonstrated that in CML patients, lymphokine-mediated killer cell activity is significantly decreased and normalizes after IFN therapy (42). Furthermore, IFN may enhance the terminal differentiation of dendritic reticulum cells capable of inducing a T-cell mediated cytotoxicity against the clonally transformed hematopoiesis $(37,38)$. Altogether, the immunomodulatory effects of IFN may not be limited to the natural immune system, but could be also relevant to adaptive responses by T-lymphocytes. Experimental data are in keeping with the finding that IFN augments the level of IL2 production by activated T-lymphocytes that may stimulate both $\mathrm{T}$-cell and NK-mediated immune responses (43). As shown in the present study, our results are in general keeping with an increase in the number of B$\mathrm{CD}_{20}{ }^{+}$and $\mathrm{T}-\mathrm{CD}_{45 \mathrm{RO}^{+}}$lymphocytes (Tables 3 and 4). This finding is believed to indicate an activation of the immunocompetent cell population, contrasting their striking reduction at onset. The second hypothesis on IFN action regards the fibrous interstitial matrix because several groups have shown definite alterations in the adhesive properties of CML progenitor cells to the marrow stroma layer. This pathomechanism may be responsible for the abnormal situation of a continuously occurring proliferation and differentiation of a (leukemic) cell population $(44-46)$ that is not subjected to the regulatory influences of the functionally complex modulation by the microenvironment $(15,16)$. In this regard, IFN may act by correcting the defective adhesion to the bone marrow stroma, which in turn restores normal regulation of progenitor cell maturation and thus restitution of non-clonally transformed hematopoiesis (17). In line with this pathogenetic model, it has been speculated that defective $\beta_{1}$-integrin-dependent adhesion is regenerated by the influence of IFN on both CML progenitors and stroma constituents $(18,19)$. In consideration of the obviously aberrant function of the stromal compartment in CML, not only macrophages (44) but also lymphocytes involved in diverse immunoregulatory processes seem to present a relevant factor contributing to the partial reconstitution of normal hematopoiesis after IFN therapy $(37,38)$.

Bone marrow lymphoid nodules are a common finding in chronic myeloproliferative disorders (4749). However, they occur at strikingly different frequencies depending on the various subtypes, revealing the highest incidence in polycythemia vera (PV) and the lowest in CML $(47,49)$. Immunohistological evaluation displays a mixture of prevalent $\mathrm{T}$ and B-lymphocytes, indicating a reactive origin as in this study $(48,49)$. Presence of these lymphoid aggregates together with circulating immune complexes gave support to the hypothesis of an im- mune component in the pathogenesis of myelofibrosis $(20-23,26)$. In addition to the generally accepted release of fibroblast-stimulating growth factors from the abnormal megakaryo- and thrombocytes $(24,25), T$-lymphocytes were speculated to play a crucial role in this rather ill-defined immunogenetic process (26). On the other hand, some caveats have to be taken into account when pursuing the hypothesis of a lymphocyte-mediated generation of myelofibrosis that has been repeatedly recognized to present a most unfavorable complication for prognosis in $\mathrm{Ph}^{1+}$-CML (50-52). Quantification of lymphoid nodules discloses that the majority are found in PV without fiber increase in the bone marrow $(47,49)$. Moreover, results of this study failed to reveal a relevant correlation of scattered $\mathrm{T}$ - or B-lymphocytes with fiber density at onset and also (and most important) did not show any relationship between progression of fibrosis (MPI) and increase in the lymphocyte population (LPI) during therapy (Tables 3 and 4).

In conclusion, the results of our immunohistologic and morphometric study on $\mathrm{CD}_{4} \mathrm{RO}^{+}$and $\mathrm{CD}^{+} 0^{+}$lymphocytes in the bone marrow of patients with $\mathrm{Ph}^{1+}$-CML during therapy are in keeping with a significant increase of this cell population in particular following IFN and HU administration. Moreover, no relevant correlations could be ascertained between quantity and numerical increase of lymphocytes and fiber density at onset or during different treatment modalities. Comparison with normal bone marrow samples revealed a lack of immunocompetent T-lymphocytes in CML, which is strikingly improved in patients showing a hematologic remission after therapy.

Acknowledgments: The authors are greatly indebted to Mrs. B. Rosenbach, Mrs. M. Wonschick, and Mrs. $H$. Tilemann for their excellent technical assistance.

\section{REFERENCES}

1. Jonas D, Lübbert M, Kawasaki ES, Henke M, Bross KJ, Mertelsmann R, et al. Clonal analysis of bcr-abl rearrangement in T-lymphocytes from patients with chronic myelogenous leukemia. Blood 1992;79:1017-23.

2. MacKinney AA, Clark SS, Borcherding W, Fizzotti M, Hong R. Simultaneous demonstration of the Philadelphia chromosome in T, B, and myeloid cells. Am J Hematol 1993;44:4852.

3. Torlakovic E, Litz CE, McClure JS, Brunning RD. Direct detection of the Philadelphia chromosome in CD20-positive lymphocytes in chronic myeloid leukemia by tri-color immunophenotyping/FISH. Leukemia 1994;8:1940-3.

4. Garichocea B, Chase A, Lazaridou A, Goldman JM. T-lymphocytes in chronic leukaemia (CML): no evidence of the bcr/abl fusion gene detected by fluorescence in situ hybridization in 14 patients. Leukemia 1994;8:1197-1201.

5. Tefferi A, Schad CR, Pruthi RK, Ahmann GJ, Spurbeck JL, Dewald GW. Fluorescent in situ hybridization studies of 
lymphocytes and neutrophils in chronic granulocytic leukemia. Cancer Genet Cytogenet 1995;83:61-4.

6. Tsukamoto N, Karasawa M, Maehara T, Okamoto K, Sakai H, Naruse T, et al. The majority of T lymphocytes are polyclonal during the chronic phase of chronic myelogenous leukemia. Ann Hematol 1996;72:61-5.

7. Haferlach T, Winkemann M, Nickenig C, Meeder M, RammPetersen L, Schoch R, et al. Which compartments are involved in Philadelphia-chromosome positive chronic myeloid leukaemia? An answer at the single cell level by combining May-Grünwald-Giemsa staining and fluorescence in situ hybridization techniques. Br J Haematol 1997; 97:99-106.

8. Advani SH, Malhotra H, Kadam PR, Iyer RS, Nanjangud G, Balsara B, et al. T-lymphoid blast crisis in chronic myeloid leukemia. Am J Hematol 1991;36:86-92.

9. Khalidi HS, Brynes RK, Medeiros LJ, Chang KL, Slovak ML, Snyder DS, et al. The immunophenotype of blast transformation of chronic myelogenous leukemia: a high frequency of mixed lineage phenotype in "lymphoid" blasts and a comparison of morphologic, immunophenotypic, and molecular findings. Mod Pathol 1998;11:1211-21.

10. Cervantes F, Villamor N, Esteve J, Montoto S, Rives S, Rozman C, et al. 'Lymphoid' blast crisis of chronic myeloid leukaemia is associated with distinct clinicohaematological features. Br J Haematol 1998;100:123-8.

11. Enright H, Davies SM, DeFor T, Shu X, Weisdorf D, Miller W, et al. Relapse after non-T-cell-depleted allogeneic bone marrow transplantation for chronic myelogenous leukemia: early transplantation, use of an unrelated donor, and chronic graft-versus-host diseases are protective. Blood 1996;88:714-20.

12. Gallardo D, García-López J, Sureda A, Canals C, Ferra C, Cancelas JA, et al. Low-dose donor $\mathrm{CD}^{+}$cells in the CD4depleted graft prevent allogeneic marrow graft rejection and severe graft-versus-host disease for chronic myeloid leukemia patients in first chronic phase. Bone Marrow Transplant 1997;20:945-52.

13. Barrett AJ, van Rhee F. Graft-versus-leukaemia. Baillière's Clin Haematol 1997;10:337-55.

14. Horny HP, Wehrmann M, Griesser H, Tiemann M, Bültmann B, Kaiserling E. Investigation of bone marrow lymphocyte subsets in normal, reactive, and neoplastic states using paraffin-embedded biopsy specimens. Am J Clin Pathol 1993;99:142-9.

15. Liesveld JL, Winslow JM, Kempski MC, Ryan DH, Brennan JK, Abboud CN. Adhesive interactions of normal and leukemic human $\mathrm{CD}_{3}{ }^{+}$myeloid progenitors: role of marrow stromal, fibroblast, and cytomatrix components. Exp Hematol 1991;19:63-70.

16. Obinata M, Okuyama R, Matsuda KI, Koguma M, Yanai N. Regulation of myeloid and lymphoid development of hematopoietic stem cells by bone marrow stromal cells. Leuk Lymphoma 1998;29:61-9.

17. Dowding C, Gordon M, Guo AP, Maison D, Osterholz J, Siczkowski M, et al. Potential mechanisms of action of interferon-alpha in CML. Leuk Lymphoma 1993;11:185-91.

18. Verfaillie CM, Hurley R, Lundell B, Zhao C, Bhatia R. Integrin-mediated regulation of hematopoiesis: do BCR/ ABL-induced defects in integrin function underlie the abnormal circulation and proliferation of CML progenitors? Acta Haematol 1997;97:40-52.

19. Bhatia R, Verfaille CM. The effect of interferon- $\alpha$ on beta-1integrin mediated adhesion and growth regulation in chronic myelogenous leukemia. Leuk Lymphoma 1998;28: 241-54.

20. Caligaris-Cappio F, Vigliani R, Novarino A, Camussi G, Campana D, Gavosto F. Idiopathic myelofibrosis: a possible role for immune-complexes in the pathogenesis of bone marrow fibrosis. Br J Haematol 1981;49:17-21.

21. Gordon BR, Coleman M, Kohlen P, Day NK. Immunologic abnormalities in myelofibrosis with activation of the complement system. Blood 1981;58:904-10.

22. Rondeau E, Solal-Celigny P, Dhermy D, Vroclans M, Brousse $\mathrm{N}$, Bernhard JF, et al. Immune disorders in agnogenic myeloid metaplasia: relations to myelofibrosis. Br J Haematol 1983;53:467-75.

23. Cervantes F, Pereira A, Marti JM, Feliu E, Rozman C. Bone marrow lymphoid nodules in myeloproliferative disorders: association with the non-myelosclerotic phases of idiopathic myelofibrosis and immunological significance. Br J Haematol 1988;70:279-82.

24. Martyré MC. TGF- $\beta$ and megakaryocytes in the pathogenesis of myelofibrosis in myeloproliferative disorders. Leuk Lymphoma 1995;20:39-44.

25. Kimura A, Katoh O, Hyodo H, Kuramoto A, Satow Y. Platelet derived growth factor expression, myelofibrosis and chronic myelogenous leukemia. Leuk Lymphoma 1995;18:237-42.

26. Bartl R, Frisch B, Wilmanns W. Potential of bone marrow biopsy in chronic myeloproliferative disorders (MPD). Eur J Haematol 1993;50:41-52.

27. Mason DY, Comans-Bitter M, Cordell JL, Verhoeven MAJ, van Dongen JJM. Antibody L26 recognizes an intercellular epitope on the B-cell-associated CD20 antigen. Am J Pathol 1990;136:1215-22.

28. Norton AJ, Ramsay AD, Smith SH, Beverley PCL, Isaacson PG. Monoclonal antibody (UCHL1) that recognises normal and neoplastic T cells in routinely fixed tissues. J Clin Pathol 1986;39:399-405.

29. Kaiserling E, Horny HP, Engst U, Walz R. Immunohistology for quantification of normal bone marrow lymphocyte subsets. Br J Haematol 1989;72:576-7.

30. Knapp W, Rieber P, Dörken B, Schmidt RE, Stein H, vd Borne AE. Towards a better definition of human leucocyte surface molecules. Immunol Today 1998;10:253-8.

31. Cordell JL, Falini B, Erber WN, Gosh A, Abdulaziz Z, MacDonald S, et al. Immunoenzymatic labeling of monoclonal antibodies using immune complexes of alkaline phosphatase and monoclonal anti-alkaline phosphatase (APAAP complexes). J Histochem Cytochem 1984;32:219-29.

32. Falini B, Martelli MF, Tarallo F, Moir DJ, Cordell JL, Gatter $\mathrm{KC}$, et al. Immunohistological analysis of human bone marrow trephine biopsies using monoclonal antibodies. Br J Haematol 1994;56:365-86.

33. Thaler J, Greil R, Dietze O, Huber H. Immunohistology for quantification of normal bone marrow lymphocyte subsets. Br J Haematol 1989;73:576-7.

34. Giralt SA, Kantarjian HM, Talpaz M. Treatment of chronic myelogenous leukemia. Semin Oncol 1995;22:396-404.

35. Hehlmann R, Heimpel H. Current aspects of drug therapy in Philadelphia-positive CML: correlation of tumor burden with survival. Leuk Lymphoma 1996;22:161-7.

36. Guilhot F, Chastangs C, Michallet M, Guerci A, Harousseau JL, Maloisel F, et al. Interferon alfa-2b combined with cytarabine versus interferon alone in chronic myelogenous leukemia. N Engl J Med 1997;337:223-9.

37. Stella CC, Cazzola M. Interferons as biologic modulators of haematopoietic cell proliferation and differentiation. Haematologica 1988;73:225-37.

38. Peschel C, Aulitzky WE, Huber C. Influence of interferon- $\alpha$ on cytokine expression by the bone marrow microenvironment - impact on treatment of myeloproliferative disorders. Leuk Lymphoma 1996;22(1 Suppl):129-34.

39. Richards SM. Interferon- $\alpha$ : results from randomized trials. Baillière's Clin Haematol 1997;10:307-18.

40. Hehlmann R, Ansari H, Hasford J, Heimpel H, Hossfeld DK, Kolb HJ, et al. Comparative analysis of the impact of risk profile and of drug therapy on survival in CML using Sokal's 
index and a new score. Br J Haematol 1997;97:76-85.

41. Gibson FM, Malkovska V, Myint AA, Meager A, GordonSmith EC. Mechanism of suppression of normal hematopoietic activity by lymphokine-activated killer cells and their products. Exp Hematol 1991;19:659-63.

42. Pawelec G, Schneider E, Ehninger G, Rehbein A, Schmidt H. Partial correction of defective generation of lymphokineactivated killer cells in patients with chronic myelogenous leukaemia after in vivo treatment with interferon- $\alpha$ (Wellferon). Cancer Immunol Immunother 1989;29:63-6.

43. Holan V, Kohno K, Minowada J. Natural human interferonalpha augments interleukin-2 production by a direct action on the activated IL-2-producing T-cells. J Interf Res 1991;11: 319-25.

44. Bhatia R, McGlave PM, Dewald GW, Blazar BR, Verfaillie CM. Abnormal function of the bone marrow microenvironment in chronic myelogenous leukemia: role of malignant stromal macrophages. Blood 1995;85:3636-45.

45. Eaves AC, Cashman JD, Gaboury LA, Kalousek DK, Eaves CJ. Unregulated proliferation of primitive chronic myelogenous leukemia progenitors in the presence of normal marrow adherent cells. Proc Natl Acad Sci U S A 1986;83:5306-10.

46. Verfaille CM, McCarthy JB, McGlave PB. Mechanisms underlying abnormal trafficking of malignant progenitors in chronic myelogenous leukemia: decreased adhesion to stroma and fibronectin but increased adhesion to the base- ment membrane components laminin and collagen type IV. J Clin Invest 1992;90:1232-41.

47. Navone R, Valpreda M, Pich A. Lymphoid nodules and nodular lymphoid hyperplasia in bone marrow biopsies. Acta Haematol 1985;74:19-22.

48. Franco V, Florena AM, Aragona F, Campesi G. Immunohistochemical evaluation of bone marrow lymphoid nodules in chronic myeloproliferative disorders. Virchows Archiv A Pathol Anat 1991;419:261-6.

49. Thiele J, Zirbes TK, Kvasnicka HM, Fischer R. Focal lymphoid aggregates (nodules) in bone marrow biopsies: differentiation between benign hyperplasia and malignant lymphoma - a practical guideline. J Clin Pathol 1999;52:294-300.

50. Lazzarino M, Morra E, Castello A, Inverardi D, Coci A, Pagnuco G, et al. Myelofibrosis in chronic granulocytic leukaemia. Br J Haematol 1986;64:227-40.

51. Dekmezian R, Kantarjian HM, Keating M, Talpaz M, McCredie KB, Freireich EJ. The relevance of reticulin stainmeasured fibrosis at diagnosis in chronic myelogenous leukaemia. Cancer 1987;57:1739-43.

52. Thiele J, Kvasnicka HM, Zirbes TK, Flucke U, Niederle N, Leder LD, et al. Impact of clinical and morphological variables in classification and regression tree-based survival (CART) analysis of CML with special emphasis on dynamic features. Eur J Haematol 1997;58:35-46. 